\title{
Influence of dog presence on the tolerance and evaluation of aversive stimulation
}

\author{
Laura Sodré Galvão Garcia ${ }^{*}$, , Isabela Zaine ${ }^{1,2}$, Camila Domeniconi ${ }^{1}$
}

Abstract

This study aimed to investigate the effects of the presence of a domestic dog in the evaluation and tolerance of auditory aversive stimulation. Eighteen undergraduate college students participated. We analysed the latency of escape response from the aversive sounds and evaluation of the session through a semantic differential in three conditions: no distractors, a book of paintings as a distractor, and a dog as a distractor. Latency of escape response was significantly higher in the presence of a dog and participants also evaluated the session more positively, suggesting that dogs can positively affect the perception of an aversive stimulation.

\section{HIGHLIGHTS}

- Animals have been used for therapeutic purposes in various settings and can influence human well-being.

- Due to the history of domestication and cooperation with humans, the dog (Canis familiaris) has the most potential to deliver benefits.

Pet Behaviour Science | 2016, Vol.2, 16 - 23

DOI: 10.21071/pbs.v0i2.4002

Laura Sodré Galvão Garcia*1, Isabela Zaine ${ }^{2}$, Camila Domeniconi $^{1}$

1. Department of Psychology. Universidade Federal de São Carlos

Paper Research

$\begin{array}{ll}\begin{array}{l}\text { 2. Instituto de Ciências Matemáticas e } \\ \text { de Computação. }\end{array} & \text { *Email: } \\ \text { Universidade de São Paulo } & \\ \text { Departamento de Psicologia } & \\ \text { Fundação Hermínio Ometto - } & \\ \text { UNIARARAS. } & \end{array}$

Brazil.

Keywords: tolerance of aversive stimulation; humananimal relationship; dog; animal-assisted intervention
- Results indicate that that the presence of a dog mitigated the sensation of discomfort felt by the participants, enabling them to show more tolerance to the uncomfortable situation.

- The present findings extend the current body of knowledge in the area of human-animal studies and have implications for animalassisted interventions.

\section{INTRODUCTION}

Animals have been used for therapeutic purposes in hospitals, nursing homes and for people with various special needs since the 9th century (Brodie and Biley 1999). Many animal species can influence human wellbeing. Health benefits from interaction with pets may be explained by the social nature of humankind. However, due to the history of domestication and cooperation with humans, the dog has the most potential to deliver benefits (Savalli and Ades 2015). In fact, the first animal to be domesticated was the dog (De Mello 2012; Larson et al. 2012; Axelsson et al. 2013). In therapeutic contexts, dogs have been used as distractors from situations that provoke emotional distress (Brickel 1982). Many studies have been conducted to understand people's emotional responses to certain kinds of aversive sounds (Zald and Pardo 
2001; Cox 2007; Cox 2008; Neumann, Waters and Westbury, 2008; Tajadura-Jiménez et al. 2010). Aversive auditory stimulation is known to stimulate the amygdala (Zald and Pardo 2001), a brain structure essentially related to emotional evaluation including the modulation of stress responses (Oken et al. 2014). However, studies on human-dog relationships investigating aversive sounds as a stressful experience are missing.

The mere presence of a dog during a task may affect physiological and/or behavioral indicators of wellbeing. House (1981) suggested that social support may reduce the perception of a stressful situation and may also tranquilize the neuroendocrine system so that individuals are less reactive to perceived stress. Social support can come from different types of sources, such as a close friend, a spouse or even an animal (Allen et al. 1991). In the last case, for example, Kotrschal and Ortbauer (2003) reported that the presence of a dog in a first grade classroom was associated to an enhancement of students' behavior of paying attention to the teacher, as well as greater cooperation and social integration among peers.

To understand the effects of the presence of domestic dogs on human health, researchers previously conducted correlational studies measuring heart beat and blood pressure (Vormbrock and Grossberg 1988; Allen et al. 1991; Eddy 1996; De Mello 1999; Allen et al. 2002; Wolff and Frishman 2004; Wells 2005) as well as questionnaires and interviews (Siegel 1990; Hoffmann, et al. 2009; Beetz et al. 2011). Despite all reports about the positive effects regarding dog-animal interactions, it is still needed to produce researches with replicable methods and operationally described measures that may lead to behavior predictions. Experimental analysis can more clearly demonstrate whether or not behavior can be attributed to environmental events. Identifying the psychophysiological procedures that underlie in the interspecific relationships may provide a picture to the probable direct effect on human health by dogs (Virues-Ortega and Buela-Casal 2006).

Based on the results of previous literature, the purpose of this study was to verify the effects of a dog's presence in the tolerance and evaluation of a situation in which the participants were exposed to aversive auditory stimuli in three different conditions. The removal of the headphone was defined as an escape response. Tolerance to the aversive stimulation was inferred by the period of time participants endured the aversive stimulation. Therefore, the longer participants remained with the headphones listening to the aversive sounds, the greater is the tolerance in relation to the sound.

\section{METHODS}

Participants

Eighteen undergraduate college students, 10 female and 8 male, aged 18 to 35 years $(M=25, S D=2.37)$ participated. Participants were self-recruited by informative flyers placed throughout the university campus. Selection criteria were that participants did not fear dogs and did not have any hearing impairments. Prior to the experiment, participants received information about the procedure, ethical concerns and signed an Informed Consent Form agreeing to participate in the research. None of the participants withdrew from the procedure and they did not receive monetary compensation. Moreover, our procedure was reviewed and approved by the Committee of Ethics in Research with Humans (protocol CAAE: 28071014.6.0000.5504) and by the Committee of Ethics in Research with Animals (protocol \# CEUA: 8077050415) of Federal University of São Carlos.

\section{Materials and setting}

The experimental sessions were conducted individually in a room $\left(2.5 \times 2.5 \mathrm{~m}^{2}\right)$ that contained a laptop, headphones and a futon for participants to sit on. The aversive stimuli, three low-pitched $(1 \mathrm{kHz} ; 1.3 \mathrm{kHz}$; $1.6 \mathrm{kHz})$, continuous, monophonic sounds, were developed using the software Audacity 2.0.5. Halpern, Blake and Hillenbrand (1986) state that sounds composed by different low-frequency notes contribute to the perception of discomfort towards the auditory stimulation. Participants were exposed only once to each one of the aversive sounds during the experiment to avoid habituation. Since we used three different aversive auditory stimuli (1,2 and 3$)$ there were six possible sequences of sound presentation, from $\mathrm{A}$ to $\mathrm{F}$, 
throughout the procedure (A: 1-2-3; B: 1-3-2; C: 2-3-1; D: 2-1-3; E: 3-2-1; F: 3-1-2). The sequence of sounds was counterbalanced across participants and conditions, as shown in Table 1 . Sounds were presented to participants via headphones connected to a laptop at 42 $\mathrm{dB}$, which is inside the limit established by the World Health Organization for sound levels heard via headphones - under $70 \mathrm{~dB}$ (Berglund, Lindvall and Schwela 1999). Depending on the experimental session, distractor stimuli, either a dog or a book with paintings and text written in Dutch were also present. We selected a book in an unfamiliar foreign language to avoid participants to engage in complex symbolic behavior, such as reading with comprehension. The dog was a one year-old male border collie previously trained to quietly lay down beside the participant and interact with him/her by eating dog treats. All sessions were videotaped for analysis of latency of removal of the headphones.

A semantic differential scale was used to access participants' evaluation of the aversive degree of the task. The semantic differential is a technique that permits measurement of the meaning of concepts, such as pictures, figures and, in our case, words (Osgood, Suci and Tannenbaum 1957). Participants had to assign Likert-type scales ranging from -3 to +3 to 10 pairs of opposite adjectives: stressful / relaxing, bad / good, uncomfortable / comfortable, irritating / enjoyable, unpleasant / pleasant, restless / calm, exhausting / stimulating, boring / exciting, disturbing / peaceful and intolerable / tolerable. Negative numbers correlate to a general negative evaluation of the task, positive numbers to positive evaluations, and zero to a neutral evaluation. For the first five pairs of adjectives, the numbers of the scale were organized from left to right starting from the number +3 , that was the highest positive number. For the next five pairs, the scale started from left to right from the number -3 , the highest negative number. This was done in order to avoid automatic responses to the numbers immediately below one another or side bias.

\section{Procedure}

All participants were exposed to three different experimental conditions, Control, Book and Dog, that were carried out once a day for three consecutive days. Participants were randomly assigned to one of six possible sequences regarding the order of the experimental conditions, as presented in Table 1. They were individually brought to the experimental room and instructed to sit on the futon. In the Control condition, they were instructed to put on the headphones and to remove them and leave the room at the first sign of discomfort. In the Book condition, the same instruction was given and the only change was that there was a book next to the futon that they could flip through while wearing the headphones. In the Dog condition, they were instructed as in Control and they were given the additional instruction that they could interact with the dog by playing with it or giving it treats while wearing the headphones. Written instructions were given to the participants prior to session beginning in order to assure that instructions were consistently delivered across participants and sessions. In all conditions the sound was already being broadcasted via headphones, so that participants would hear it immediately upon wearing the headphones. We evaluated the tolerance of the aversive sounds by the latency until removing the headphones, measuring the amount of time that elapsed. After each condition, participants answered the semantic differential in order to assess their evaluation about the session.

Table 1. Experimental conditions sequence assigned to participants. Sound sequences were A: 1-2-3; B: 1-3-2; C: 2-3-1; D: 2-1-3; E: 3-2-1; F: 3-1-2.

\begin{tabular}{ccc}
\hline Participants & Experimental Sequence & Sound sequence \\
\hline P1 & & A \\
P2 & Dog-Book-Control & B \\
P3 & & C \\
\hline P4 & Dog-Control-Book & E \\
P5 & & F \\
P6 & & A \\
P7 & B \\
P8 & & Control-Dog-Book \\
P9 & & D \\
P10 & E \\
P11 & Control-Book-Dog & F \\
P12 & & A \\
P13 & & B \\
P14 & Book-Control-Dog & C \\
P15 & & D \\
P16 & & E \\
P17 & Book-Dog-Control & F \\
P18 & &
\end{tabular}




\section{Data Analysis}

Tolerance to the aversive auditory stimuli was analyzed using the latency to escape from the aversive stimuli, which corresponded to the time elapsed between the participants' positioning of the headphones and its removal. One-way between conditions analysis of variance (ANOVA) for correlated samples was used to compare the average latencies across experimental conditions and participants' scores on the semantic differential, followed by post-hoc Tukey HSD tests to compare the two conditions with each other. Pearson correlation tests were conducted between the latencies of escape response and scores on the semantic differential scale. All statistical analysis were two-tailed with a confidence level of 0.05. The data was analyzed using the statistical software SPSS version-20.

\section{RESULTS}

Participants showed a higher average of latency to remove the headphones in the Dog condition $(\mathrm{M}=24.4$ min, SD = 10.6), followed by the Book $(M=20.9 \mathrm{~min}, \mathrm{SD}$ $=11)$ and Control conditions $(\mathrm{M}=15.1 \mathrm{~min}, \mathrm{SD}=6.3)$. This difference across conditions was statistically significant (One-way ANOVA, $\mathrm{F}_{2,34}=4.1$, $\mathrm{p}<0.02$ ). These results indicate that, in general, participants in the Dog condition tolerated the aversive stimulation for longer periods of time. However, there was some variability. For example, latency from two participants significantly differed from the group mean: one participant from the Book condition presented the highest latency score, enduring the aversive stimulation for $50 \mathrm{~min}$; and one participant from the Control group presented the lowest latency score, by immediately removing the headphones.

The post-hoc Tukey HSD test indicated that the latency to remove the headphones was significantly higher only when comparing Dog vs. Control ( $p<0.05)$ but no significant difference was found between Dog vs. Book and Book vs. Control conditions. This means that although participants usually endured the aversive stimulation for a longer period of time in the Dog condition, the dog was not a significantly better distractor than the book. On the other hand, having the book of paintings as a distractor did not significantly alter the latency in the escape response when compared to the group that was not provided with any distractors. Participants' average latencies to remove the headphones across experimental conditions are shown in Figure 1.

Figure 1. Average latency of escape response in the Control, Book and Dog experimental conditions. Columns represent mean values. *Tukey HSD test with $\mathrm{p}<0.05$. Error bars represent standard deviation.

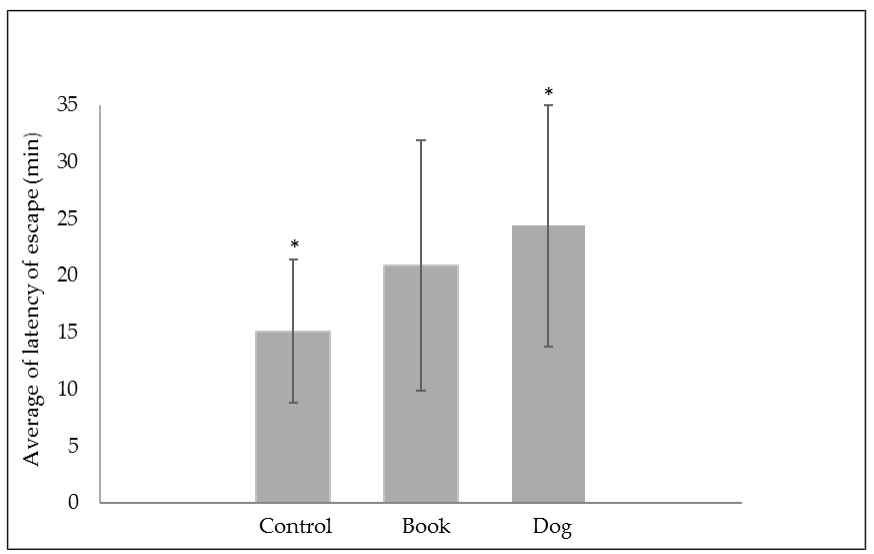

Participants' scores in the semantic differential also differed across the three experimental conditions. Figure 2 shows the medians of the evaluations in each experimental condition. Participants tended to give more positive evaluations in the Dog condition $(\mathrm{M}=$ $1.2, \mathrm{SD}=1.3$ ) and negative evaluations for the Book and Control conditions $(\mathrm{M}=-0.62, \mathrm{SD}=1.4$ and $\mathrm{M}=-0.02$, $\mathrm{SD}=1.8$, respectively). The difference across conditions was statistically significant (One-way ANOVA, $\mathrm{F}_{2,358}=71.2, \mathrm{p}<0.001$ ), with scores being significantly higher in the Dog condition when compared to the Book and Control conditions and in the Book condition compared to Control (Tukey HSD test, $\mathrm{p}<0.01$ ).

Pearson correlation was used to calculate latency of escape response and the mean scores in the semantic differential to access the relationship between tolerance to the aversive sounds and evaluation of the sessions. There was a positive, though weak, correlation between the two variables $(\mathrm{r}=0.34, \mathrm{n}=54, \mathrm{p}=0.009)$, meaning that participants who took longer to remove the headphones also tended to evaluate the sessions as more positive. These results are summarized in Figure 3. 
Figure 2. Median values of the semantic differential scale of the experimental sessions across different conditions (Control, Book and Dog).

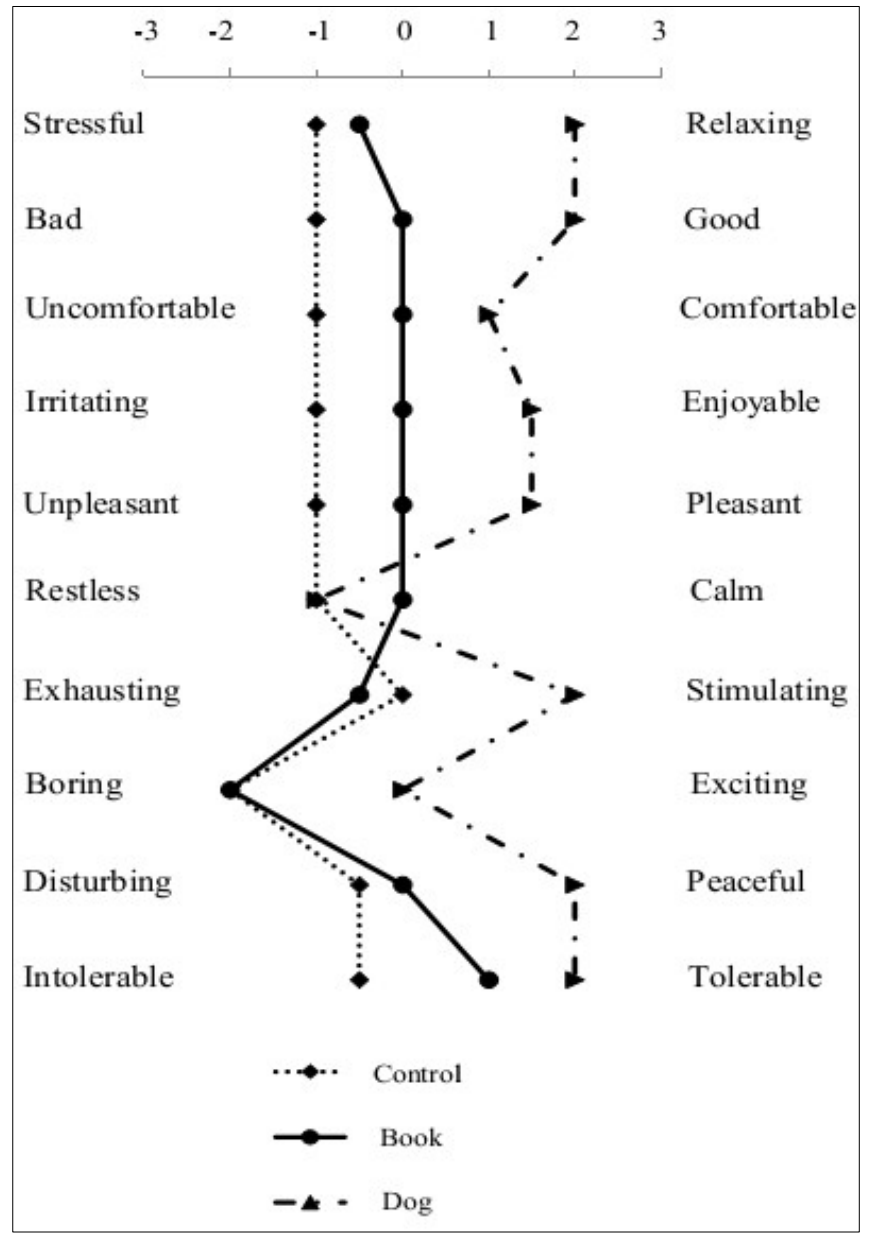

The scatter plot was sectioned in four quadrants based on the medians of evaluation scores on the semantic differential and average latency of escape response. It can be observed that in the upper right quadrant, which represents the higher evaluations and latency of escape response, the predominant data points refer to the Dog condition. This result indicate that although participants from the Dog condition were exposed for more time to the aversive sounds, they also tended to evaluate the session using more positive describers of subjective private states. On the other hand, in the lower left quadrant, that represents the lowest evaluation scores and latency, the more prevalent data points represent scores from Control condition, which indicate that when no distractors were available, participants tended to evaluate the session more negatively and endured the aversive stimulation for less time.

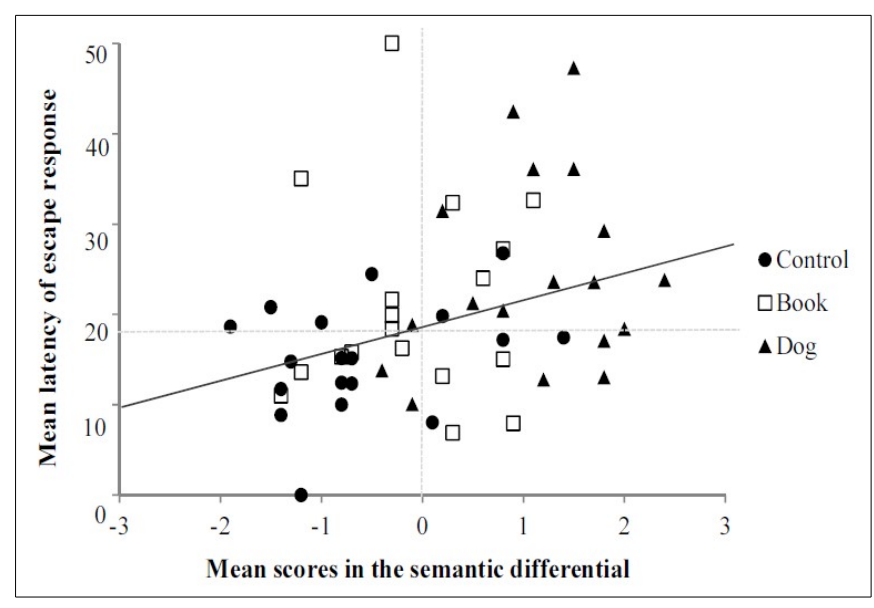

Figure 3. Correlation between latency until escape response and mean scores in the semantic differential. Tendency line represents Pearson correlation, $r=0.34$. Dashed lines indicate the median values of the semantic differential score and latency to emit the escape response.

\section{DISCUSSION}

Our study aimed to investigate the impact of the presence of a dog in the tolerance and evaluation of aversive auditory stimulation. The results show that participants in the presence of a dog took significantly longer time to emit an escape response from the aversive sounds than in the Control condition. Moreover, they tended to evaluate the situation with the dog as more positive than when the distractor was a book of pictures or when there was no distractor available. Also, there was a positive correlation between the latency of escape response from the aversive stimuli, experimental condition and evaluation of the session. In general, participants that rated the session as more positive also endured the aversive stimulation for a longer period of time, and the experimental condition that favoured higher latencies before the interruption of the aversive stimuli was the Dog condition. Our results corroborate other findings in the literature that point out that the short-term interactions with domesticated animals, dogs included, may decrease signs of physiological and behavioural distress (Allen et al. 1991; Odendaal 1999; Hunt and Chizkov 2014) and increase tolerance to aversive stimulation (Kanfer and Goldfoot 1966; Peyron et al. 1999).

As presented by Savalli and Ades (2015), health benefits from interaction with pets may be explained by 
the social nature of humankind. As such, humankind needs social acquaintances and, more than that, has the necessity of physical contact with living organisms. Albeit the necessity of positive interactions exists in behavioral patterns of many living organisms, the need of attention becomes clearly identified only in advanced and social beings, as if it was a universal emotion, as stated by Odendaal (2000). This may explain the fact that participants' tolerance to the aversive stimuli did not significantly differ between Control and Book conditions, but differed between Dog and Control, suggesting that the Dog was a stronger distractor, while the book of paintings did not significantly enhance participants' tolerance to the aversive sounds. Also, Vormbrock and GrossBerg (1988) discussed that interactions with dogs might be less stressful than people due to classic conditioning because most people interact with pets in relaxed situations. Thus the dog may be generally associated with activities that are positively reinforcing.

To finalize, there are some limitations worth discussing. The first issue relates to the quality of the aversive stimuli here utilized. For ethical reasons we deliberately did not to use noxious or painful stimuli in our procedure. For definition, escape responses correspond to responses that lead to the interruption or termination of an ongoing aversive stimulation (Catania, 1999). This way, escape responses are only emitted in the presence of aversive stimulation. We consider that any stimulation that a person behaves in order to escape is considered aversive (Cooper et al. 2007), therefore, any noise that a person works to escape from can be considered aversive, which is the case of the sounds we used. Also, there is evidence that continuous low-frequency sounds are usually perceived with discomfort (Halpern et al. 1986). Although, participants from the Control and Book conditions tended to use more negative describers, the adjective "boring" was the most frequent and salient one in subjects evaluation in the semantic differential scale. This might indicate that the sounds we used as aversive stimuli might have only been mildly aversive; therefore, participants were able to tolerate them for some time, with variation, in all experimental conditions. We consider that future research on this topic should use auditory aversive stimuli that have been empirically validated to control for these possible confounding variables. Another possible limitation of our study was acoustic insulation. Although the surroundings of the experimental room were relatively quiet and people were not allowed to transit in this area when the experimental sessions were ongoing, and the participants were wearing headphones, the experimental room was not soundproof. This way, it is possible that other sounds from the outside may have interfered at some level. A final concern refers to participants' hearing. An inclusion criterion to our experiment was that participants did not have any hearing impairments, a condition that was self-stated. Thus, future work might include audiometric screening of participants.

\section{CONCLUSION}

Overall our study shows that the presence of a dog had a positive effect on the tolerance. Here, we proposed an experimental study on the function of a dog as a distractor in the tolerance of aversive auditory stimulation, that are easily operationalized and replicable not only in experimental, but also in clinical and educational interventions. It would be interesting, though, to also include physiological measures of distress as complimentary data to gain a more comprehensive appraisal of the phenomenon.

\section{ACKNOWLEDGEMENTS}

Isabela Zaine was supported by a doctoral fellowship (FAPESP, Grant\# 2011/06288-0). Camila Domeniconi was supported by Research Productivity Grants from CNPq.

\section{REFERENCES}

Allen, K.M., Blascovich, J., Tomaka, J., and Kelsey, R.M. 1991. Presence of human friends and pet dogs as moderators of autonomic responses to stress in women. Journal of Personality and Social Psychology 61(4): 582-589, doi: 10.1037//0022-3514.61.4.582

Allen, K., Blascovich, J., Wendy, B., and Mendes, R.S. 2002. Cardiovascular reactivity and the presence of pets, friends, and spouses: the truth about cats and dogs. Psychosomatic Medicine 64: 727-739, doi: 10.1097/01 
Axelsson, E., Ratnakumar, A., Arendt, M.L., Maqbool, K., Webster, M., Perloski, M., Liberg, O., Armeno, J.M., Hedhammar, A. and Lindblad-Toh, K. 2013. The genomic signature of dog domestication reveals adaptation to a starch-rich diet. Nature 495: 360-364, doi: 10.1038/nature11837

Beetz, A., Kotrschal, K., Turner, D.C., Hediger, K., Uvnäs-Moberg, and K. Julius, H. 2011. The effect of a real dog, toy dog and friendly person on insecurely attached children during a stressful task: an exploratory study. Anthrozoos 24: 349-368, doi: 10.2752/175303711X13159027359746

Berglund, B., Lindvall, T., and Schwela, D. H. 1999. Guidelines for community noise. World Health Organization, Geneva.

Brickel, C.M. 1982. Pet-facilitated psychotherapy: a theoretical explanation via attention shifts. Psychological Reports 50: 71-74, doi: 10.2466/pr0.1982.50.1.71

Brodie, S.J., and Biley, F.C. 1999. An exploration of the potential benefits of pet-facilitated therapy. Journal of Clinical Nursing 8(4): 329-337. doi:10.1046/j.13652702.1999.00255.x

Catania, A. C. 2007. Learning. Cornwall-on-Hudson, NY: Sloan.

Cooper, J.O., Heron, T.E., and Heward, W.L. 2007. Applied behavior analysis. ( $2^{\text {nd }}$ edition). Upper Saddle River, NJ: Pearson Education.

Cox, T.J. 2007. The effect of visual stimuli on the horribleness of awful sounds. Applied Acoustics 69(8): 691-703, doi: 10.1016/j.apacoust.2007.02.010

Cox, T.J. 2008. Scraping sounds and disgusting noises. Applied Acoustics 69: 1195-1204, doi: 10.1016/j.apacoust.2007.11.004

De Mello, L.R. 1999 The effect of the presence of a companion-animal on physiological changes following the termination of cognitive stressors. Psychology $\mathcal{E}$ Health 12: 859-868, doi: 10.1080/08870449908407352
De Mello, M. 2012. Animal and society: an introduction to human-animal studies. Columbia University Press.

Eddy, T.J. 1996. RM and Beaux: Reductions in cardiac activity in response to a pet snake. Journal of Nervous and Mental Disease 184(9): 573-575.

Halpern, D.L., Blake, R. \& Hillenbrand, J. 1986. Psychoacoustics of a chilling sound. Perception $\mathcal{E}$ Psychophysics 39 (2): 77-80.

Hoffmann, A.O.M., Lee, A.H., Wertenauer, F., Ricken, R., Jansen, J.J., Gallinat, J. and Lang, U.E. 2009. Dogassisted intervention significantly reduces anxiety in hospitalized patients with major depression. European Journal of Integrative Medicine 1: 145-148, doi: 10.1016/j.eujim.2009.08.002

House, J. S. 1981. Work stress and social support. Reading, MA: Addison-Wesley.

Hunt, M. and Chizkov, R. 2014. Are therapy dogs like Xanax? does animal-assisted therapy impact processes relevant to cognitive behavioral psychotherapy? $\begin{array}{llll}\text { Anthrozoös } & 27 & \text { (3): } & 457-469,\end{array}$ $10.2752 / 175303714 X 14023922797959$

Kanfer, F.H., and Goldfoot, D.A. 1966. Self-control and tolerance of noxious stimulation. Psychological Reports 18: 79-85, doi: 10.2466/pr0.1966.18.1.79

Kotrschal K., Ortbauer B. 2003. Behavioral effects of the presence of a dog in a classroom. Anthrozoös 16: 147159 doi: $10.2752 / 089279303786992170$

Larson, G., Karlsson, E.K., Perria, A., Webster, M.T., Ho, S.Y.W., Peters, J., Stahl, P.W., Piper, P.J., Lingaas, F., Fredholm, M., Comstock, K,E., Modiano, J.F., Schelling, C., Agoulnik, A.I., Leegwater, P.A., Dobney, K., Vignes, J-D., Vilàt, C., Anderssond, L. and Lindblad-Tohb, K. 2012. Rethinking dog domestication by integrating genetics, archeology, and biogeography. Proceedings of the National Academy of Sciences 109(23): 8878-8883, doi: 10.1073/pnas.1203005109 
Martin, F., and Farnum, J. 2002. Animal-assisted therapy for children with pervasive developmental disorders. Western Journal of Nursing Research 24(6): 657670, doi: 10.1177/019394502320555403

Neumann, D.L., Waters, A.M. and Westbury, H.R. 2008. The use of an unpleasant sound as the unconditional stimulus in aversive Pavlovian conditioning experiments that involve children and adolescent participants. Behavior Research Methods 40 (2): 622-625, doi: 10.3758/BRM.40.2.622.

Odendaal, J.S.J. 1999. A physiological basis for animalfacilitated psychotherapy. $\mathrm{PhD}$ thesis, University of Pretoria.

Odendaal, J.S.J. 2000. Animal assisted therapy: magic or medicine? Journal of Psychosomatic Research 49(4): 275280, doi: 10.1016/s0022-3999(00)00183-5

Oken, B.S., Chamine, I. and Wakeland, W. 2014. A Systems approach to stress, stressors and resilience in humans. Behavioural brain research 282: 144-154, doi:10.1016/j.bbr.2014.12.047

Osgood, C.E., Suci, G.J. and Tannenbaum, P.H. 1957. The measurement of meaning. University of Illinois: Urbana.

Peyron, R., Garcia-Larrea, L., Gregoire, M.C., Costes, N., Convers, P., Lavenne, F., Mau-guiere, F., Michel, D., and Laurent, B. 1999. Haemodynamic brain responses to acute pain in humans: sensory and attentional networks. Brain 122: 1765- 1780, doi: 10.1093/brain/122.9.1765

Prothmann, A., Ettrich, C. \& Prothmann, S. 2009. Preference of, and responsiveness to people, dogs and objects in children with autism. Anthrozoos 22: 161-171.
Sams, N. J., Fortney, E. V. \& Willenbring, S. 2006. Occupational therapy incorporating animals for children with autism: a pilot investigation. American Journal of Occupational Therapy 60(3): 268-274.

Savalli, C. and Ades, C. (2015). Benefícios que o convívio com um animal de estimação pode promover para a saúde e bem estar do ser humano. In: Marie Odile Monier Chelini; Emma Otta. (Org.). Terapia Assistida por Animais, Barueri, SP, pp. 23-43.

Siegel, J.M. 1990. Stressful life events and use of physician services among the elderly: The moderating role of pet ownership. Journal of Personality and Social Psychology 58: 1081- 1086.

Tajadura-Jiménez, A., Väljamäe, A., Asutay, E., and Västfjäll, D. 2010. Embodied auditory perception: the emotional impact of approaching and receding sound sources. Emotion 10: 216-229, doi: 10.1037/a0018422

Virues-Ortega, J., and Buela-Casal, G. 2006. Psychophysiological effects of human-animal interaction: theoretical issues and long-term interaction effects. Journal of Nervous and Mental Diseases 194(1): 5257, doi: 10.1097/01.nmd.0000195354.03653.63

Vormbrock, J.K., and Grossberg, J.M. 1988. Cardiovascular effects of human-pet dog interactions. Journal of Behavioral Medicine 11: 509-517, doi: 10.1007/bf00844843

Wells, D.L. 2005. The effect of videotapes of animals on cardiovascular responses to stress. Stress and Health 21: 209-213, doi: 10.1002/smi.1057

Wolff, A.I. and Frishman, W.H. 2004. Animal-assisted therapy in cardiovascular disease. Seminars in Integrative Medicine 2: 4, 131-134.

Zald, D.H. and Pardo, J.V. 2001. The neural correlates of aversive auditory stimulation. NeuroImage 16: 746753, doi:10.1006/nimg.2002.1115 